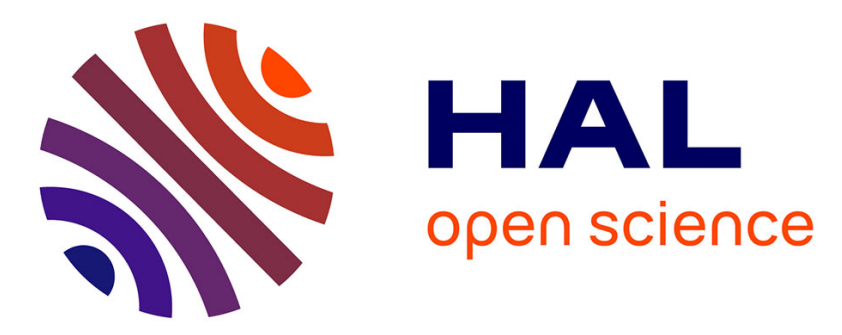

\title{
Learning to Lead Online Collaborations: Insights from Student-Based Global Virtual Teams Between UK and Norway
}

Niki Panteli, Tor Atle Hjeltnes, Knut Arne Strand

\section{- To cite this version:}

Niki Panteli, Tor Atle Hjeltnes, Knut Arne Strand. Learning to Lead Online Collaborations: Insights from Student-Based Global Virtual Teams Between UK and Norway. 18th Conference on e-Business, e-Services and e-Society (I3E), Sep 2019, Trondheim, Norway. pp.785-796, 10.1007/978-3-030-293741_64. hal-02510107

\author{
HAL Id: hal-02510107 \\ https://hal.inria.fr/hal-02510107
}

Submitted on 17 Mar 2020

HAL is a multi-disciplinary open access archive for the deposit and dissemination of scientific research documents, whether they are published or not. The documents may come from teaching and research institutions in France or abroad, or from public or private research centers.
L'archive ouverte pluridisciplinaire HAL, est destinée au dépôt et à la diffusion de documents scientifiques de niveau recherche, publiés ou non, émanant des établissements d'enseignement et de recherche français ou étrangers, des laboratoires publics ou privés. 


\title{
Learning to Lead Online Collaborations: Insights from Student-based Global Virtual Teams between UK and Norway
}

\author{
Niki Panteli ${ }^{1}$, Tor Atle Hjeltnes ${ }^{2}$ and Knut Arne Strand ${ }^{2}$ \\ ${ }^{1}$ Royal Holloway University of London, London, England \\ ${ }^{2}$ Norwegian University of Science and Technology, Trondheim, Norway \\ knut.a.strandentnu.no
}

\begin{abstract}
In this paper we present a virtual collaborative student project across two universities in the UK and Norway. The students involved were all Master students in Digital Innovation \& Analytics and Digital Collaboration retrospectively. The project also had an industry partner, Cisco, and was set up as part of students' learning in their corresponding universities. Five student-based Global virtual teams (GVTs) were formed. We draw on the experiences of these GVTs to gain better understanding of students' experiences in dispersed collaboration giving particular focus on the leadership practices adopted in student-based GVTs. Our analysis of the GVT members' experiences and reflections show that the way leadership was enacted had a role to play in the collaboration within the GVT. Overall, students appreciated being given the opportunity to be part of a globally dispersed project and were able to identify lessons learned and skills that they gained from the experience. Further, students were able to get practical experience in being part of virtual teams and to implement some of the ideas and approaches that they have learned from theory and in class discussions. For example, personal qualities that are central to success in virtual teams, i.e. communication skills, intercultural skills, interpersonal skills, methodological and technical skills, team working skills and leadership skills.
\end{abstract}

Keywords: Global Virtual Teams, Collaboration, Leadership, Dispersed Projects, Pedagogy.

\section{Introduction}

Technological advancements as well as an organisational interest in recruiting talent regardless of location, has contributed to the increasing use of globally dispersed virtual teams. It is therefore not surprising that university lecturers, especially within the Information Systems discipline, have been setting up global virtual student projects in order to expose students to the opportunities and challenges of working in virtual teams. Such projects necessitate a virtual collaboration where students from different universities are often asked to work on a project as part of their assessment within a specific timeframe. The task mandates the use of web-based technologies and a cooperative 
effort on the part of all team members who are then often assessed as a group. Organising student-based global virtual teams (GVTs) offer opportunities for enhancing teaching and learning practice as well as for enabling students to gain skills in managing and leading effectively in the online space [9] which ultimately contribute to increasing their employability and career development. In this paper, we present one such project between a university in the UK and a university in Norway that have among others the purpose of encouraging students to learn about leading online collaborations and developing effective dispersed collaborations in general. Drawing on this project, we aim to develop a better understanding of the leadership practices adopted in student based GVTs in order to develop effective collaborations in the dispersed setting. Though numerous pedagogical studies exist to-date on student-based globally dispersed teams, this is the first study to our knowledge that takes a focus on leadership specifically examining how students may develop their leadership capability in the online setting.

Following this introduction, we review the relevant literature on student-based GVTs, collaboration and leadership in the virtual team context. We then describe our GVT and the involvement of the two universities in this endeavour and explore the key themes that we have encountered in this project, illustrated by student comments and insights. Finally, we present what we consider are effective leadership approaches in the student-based GVTs and identify recommendations to other instructors for organising successful GVTs.

\section{$2 \quad$ Student-based Global Virtual Teams}

Many university instructors now engage with their students through diverse virtual learning platforms. These mediated environments may be restricted to within country designs $[2,15]$ or to between two or more countries [8, 16, 24, 25] as part of a student's learning process. The latter contribute to the emergence of global virtual teams. These are teams that consist of globally dispersed students who work on a joint project in a technology-mediated environment. In this way, collaboration in student-based GVTs are carried out across time and space as well as across organizational boundaries adding diversity to students' project teams. For the instructors, online collaborative tools such as Blackboard, Moodle and WebCT among others, have enabled the design of numerous virtual student-based projects often at a global scale providing opportunities for innovations in teaching and learning.

A study by Alavi et al [2] that compared two distributed courses (one with campusbased students and the other with non-proximate distant students) with a traditional classroom based course, found that the students involved in the distant distributed course shown higher levels of critical thinking skills. Similarly, Piccoli et al. [19] in a study on the effectiveness of web-based learning environments found that learning in such environments has fostered increased computer self-efficacy among students. Virtual student teams are important for enhancing students' learning as well as for giving insights into virtual team dynamics by simulating work based scenarios that our students are likely to experience in the 'real' world. In this way, such practices equip students with necessary skills in how to manage effectively virtual team projects and 
online collaborations [9]. In what follows, we discuss two key factors for the success of GVTs: collaboration and leadership.

\section{Collaboration}

In a globally distributed environment collaboration between the dispersed team members rely heavily on digital technologies to achieve common outputs. Within this setting, limited social cues restrict the occurrences of familiarity and trust development whilst raise the likelihood of misunderstanding and conflicts that have negative effect on effectiveness and efficiency of collaborative teamwork and team dynamics [13]. Though misunderstandings occur in collocated teams too, it is aspects of virtual teams such as time differences, delays in information exchange and limited social cues that can exacerbate conflict [7]. It is often assumed that due to the greater diversity of members' backgrounds in GVTs [23], but also the computer-mediated nature of GVT's communications [1], the likelihood for conflicting goals and opinions are greater. Research has also suggested that such teams are more likely to suffer from problems of information distribution [6], more likely to face difficulties in creating and maintaining good working relationships, and more likely to have problems developing trust in each other [11]. It follows, therefore, that developing effective collaborations over distance in a technology-mediated setting becomes a major challenge for GVTs.

Collaboration implies that a shared end result is achieved by mutual effort of different parties (individuals, teams, organisations) involved in a collaboration process. However, there are different ways to collaborate towards achieving the shared end result. For example, teams involved in collaborative projects can work together or separately. Linked to this, existing literature has distinguished between two different collaboration patterns: interdependent mutual engagement (i.e. working together) and independent cooperative work (i.e. working separately). The former implies joint orchestrated effort and involves communication in sense of dialogue and group discussion. The latter implies that the process of achieving the shared outcome is subdivided in tasks and takes the form of cooperative working achieved through division of labour [22]. Nevertheless, regardless of the differences between these patterns, effective collaboration should maintain mutual influence between the different parties involved in the collaborative arrangement. To reinforce this, we adopt Robey et al's [21] 'intertwine' concept . According to them: "First, intertwining literally refers to the weaving, braiding, and entangling of filaments such as silk, wool or hair. ... Second, intertwining figuratively means 'mutually involved' ... [this] not only suggests that separate elements are engaged, but also that each element's contribution depends on its reciprocal involvement with the other element" [21, p. 118]. In their study, they identify four key features of intertwining: reinforcement, complementarity, synergy and reciprocity. Their approach in relation to our present study suggests that the different parties that engage in collaborative activities are not substitutes, but interacting influences. Table 1 presents the key dimensions of the intertwining effect and shows their relevance to GVT students' collaborations. 
Table 1. Key Features of Intertwining and Relevance to VT students' Collaborations.

\begin{tabular}{|l|l|l|}
\hline Feature & Definition & $\begin{array}{l}\text { Relevance to GVT collabora- } \\
\text { tive projects }\end{array}$ \\
\hline Reinforcement & $\begin{array}{l}\text { Each element amplifies the } \\
\text { effect of the other element. }\end{array}$ & $\begin{array}{l}\text { The combination of the different } \\
\text { parties' activities and idea which } \\
\text { provide potentials for new ideas } \\
\text { and activities. }\end{array}$ \\
\hline Complementarity & $\begin{array}{l}\text { The strengths of the one } \\
\text { complement the other's } \\
\text { weakness. }\end{array}$ & $\begin{array}{l}\text { The strength is the ability to ex- } \\
\text { change information and } \\
\text { knowledge regardless of time } \\
\text { and space. }\end{array}$ \\
\hline Synergy & $\begin{array}{l}\text { The combination of ele- } \\
\text { ments create new proper- } \\
\text { ties which did not previ- } \\
\text { ously exist }\end{array}$ & $\begin{array}{l}\text { Going beyond the boundaries of } \\
\text { their university programme and } \\
\text { which encompasses characteris- } \\
\text { tics of each different subgroup, } \\
\text { contributing to new ideas and } \\
\text { opportunities. }\end{array}$ \\
\hline Reciprocity & $\begin{array}{l}\text { The elements are mutually } \\
\text { interdependent and that } \\
\text { there is an equal partner- } \\
\text { ship between them, rather } \\
\text { than a leader-follower rela- } \\
\text { tionship. }\end{array}$ & $\begin{array}{l}\text { Both parties co-exist equally; } \\
\text { the one is not more important } \\
\text { than the other. }\end{array}$ \\
\hline
\end{tabular}

Our first proposition following the above discussion is:

Proposition 1: Effective collaboration in student-based GVTs has an intertwining effect.

\section{$4 \quad$ Leadership}

Literature on leadership and virtual teams has identified three types of leaders within this context: appointed or designated leaders, emergent leaders and shared leaders. With regard to the former, for example, Kayworth and Leidner [12] studied 13 studentbased virtual teams which contained at least one designated team leader from each participant university. They explain the choice of the appointed leaders as follows: "high levels of prior work experience among team leaders helped to ensure a more realistic setting for the study" (p.13). Having an appointed leader also has disadvantages: Firstly it means that the researchers (or instructors as it was in this case) do not allow any team member to gradually and naturally emerge as a leader; and secondly by allocating team leaders' roles in a team, this has an immediate effect on team interactions.

Further, other studies have elicited that leaders emerge from the interactions that take place within the virtual team (e.g. [4]). These authors suggest that for a member to become a leader, he or she should actively participate in several activities within the 
group, make fruitful contributions to discussions and exert leadership and management skills such as encouraging other members to take part and develop coordination among members' interaction [20]. The frequency with which virtual team leaders [26] communicate with their team members has been seen as an indication of effective leadership.

More recently, studies have also pointed to evidence of shared leadership. Chamakiotis and Panteli [5] for instance have shown in their study of GVTs in an industry-academia collaboration project that several individuals may enact the role of a leader depending on their expertise and the stage of the project. They also shown that different leaders may co-exist to support different aspects of the project. From a learning perspective, it is our view that all students should be given the opportunity to develop leadership skills online as this will be important for their employability and career development in an increasingly global and virtual workplace.

Moreover, in their attempt to identify effective leadership practices, some researchers have referred to key phases of the virtual team lifecycle, describing the practices that leaders should adopt during each phase in terms of facilitating interactions, developing synergies and improving the overall team performance [27, 28]. According to this literature, the three phases of the virtual project lifecycle include: the welcoming, performing and wrapping up phases. In the welcoming phase, the general purpose or mission of the team is clarified, with resources and roles being allocated. Due to the members' diversity and dispersion, it is important at this early stage to embark on a socialisation process so as to promote synergies and shared understanding of the goals of the team. During the performing phase, team members are expected to complete the tasks assigned, attend meetings, report back to the team and share their work in progress with other members. The performing phase also involves the team moving the goal forward and meeting deadlines. Once action is underway, the virtual leader will provide the team with feedback about the task and their performance. Motivating the team should occur on a continual basis. Further, there should be acknowledgement of and communication about what has been completed towards reaching the team's goals during this phase. Finally, during the wrapping up phase the overall success of the team is celebrated and members are prepared for redeployment to another team. The extant literature has emphasised the role of the virtual team leader during all three stages of the virtual team lifecycle. For example, the ability to develop trust $[10,17]$ has been showed to be an essential characteristic of effective GVT leaders [14, 28]. Following from this discussion the second proposition of our paper is:

Proposition 2: Leadership has a significant impact on the effectiveness of studentbased GVT collaborations.

We examine these issues by focusing on a specific GVT project that involved students from two universities, in the UK and Norway. 


\section{The student based Global Virtual Team Project between UK and Norway}

The project was a collaboration between Royal Holloway University of London (RHUL) and the Norwegian University of Science and Technology (NTNU) and took place in the Spring Term of the academic year 2018-19. In particular, Master programme students from both universities (Master in Digital Innovation and Analytics and Master in Digital Collaborations respectively) were asked to work on a group project. The project had a four week duration; it officially started on February 1st and the deliverable was due on February 27th. In total, there were 32 students involved, 22 at RHUL and 10 at NTNU. The RHUL students belonged to multiple ethnicities and consisted of an international cohort from countries including India, China, Thailand, South Korea, Singapore, Brazil, Japan, Russian, Romania and UK. The 32 students were split into five teams; 3 of the teams consisted for 6 members (4 RHUL and 2 NTNU) whilst two teams consisted of 5 RHUL and 2 NTNU members). The teams had no prior history and were not expected to work together again in the future. CISCO became the industry partner for this collaborative project. The partner had a dual role; first it offered access to a cisco web-conferencing system, Cisco webex; and second, it provided topics for the students to work on. The themes allocated involved topical issues that the business world faces and all related to different aspects of collaboration technologies.

Both sets of students were attending a course or degree programme on Digital Collaborations. They were told that the purpose of the project was to encourage them to acquire specialized knowledge by applying what was covered in the course whilst giving them the opportunity to extend them academic knowledge of the subject by working on a specific online collaborative team project. The project was not just for assessment - it was part of deepening what they have learnt during the lectures whilst giving them the opportunity to gain practical skills by working on a real virtual project.

Each group worked on a topic sponsored by Cisco and had access to Cisco Webex for their online group collaborations. Under current GDPR (General Data Protection Regulation) they needed to opt in to use the Cisco tool. Each team was given a different topic to work on, but all topics were on different aspects and or different sectors where digital collaborations were used. The groups also had the opportunity to organise one virtual coaching session with a Cisco collaboration Technology expert to get formative feedback on their progress. It was up to each group to make the arrangements for this meeting themselves. The formal deliverable of the project was a 20 minutes presentation on their assigned VPT topic. The RHUL students were assessed on this presentation as well as on their ability to respond to questions linked to the presentation. Overall, the performance of all five teams that participated in the collaborative project was rated by the RHUL instructor between good to excellent; no team was assessed poorly.

Drawing on their VPT experience, the RHUL students were asked to write an individual reflection report with a focus on: "Leading successful virtual teams whilst promoting collaboration and creativity among its members", which they submitted a month after the group presentations took place. The NTNU students were asked to give a presentation on the VPT experience and to clearly identify the opportunities and chal- 
lenges of being part of a VPT and lessons learned. All the VPTs gave a good presentation that gave clarity to how they experienced working in a VPT. The students from NTNU all said that working in a VPT was interesting and relevant to their education and future job, regardless of the opportunities and challenges they had met.

\subsection{Communication Medium}

With Cisco as the industry partner for this GVT project, the students were given access to the Cisco web conferencing tool: Webex Teams. A link was sent to all students prior to the commencement of the project that was guided them to an online training on how to use the medium. The students were encouraged to use this medium for their videoconferencing meetings with their dispersed partners. However, their communication was not restricted to this medium and each VPT could incorporate other media too:

"The team used Web-ex to carry out video calls, however, the platform had minor glitches and Messenger was used as a supporting communication tool. Additionally, the team used Google Docs to share and live-update files as Web-ex did not have that option" (GVT5, Y).

\subsection{Leadership and Collaboration in the RHUL - NTNU GVT project: Evidence from the five GVTs}

The study examined the case of five global virtual teams were examined formed as a result of a collaborative project between two universities in the UK and Norway. The GVTs were characterised by a high degree of geographical and cultural dispersion and experienced time and language differences, limited homogeneity among team members in different organizations and temporality. By drawing on the intertwining concept (table 1) and its core dimensions), it is notable that there was evidence of the reciprocity and complementarity dimensions in most if not all of the teams. In their group presentations, two of the groups clearly identified the contribution made by their Norwegian collaborators, e.g. technology or industry examples: "These examples were provided to us by our Norwegian members" (GVT 1). In the case of GVT4, there was also evidence of complementarity and synergy developing their collaboration where expertise from the different subgroups in the two university was united to develop new ideas and knowledge: "Our Norwegian collaborator guided us through the topic as he had prior experience with it" (GVT 4, Yu).

\subsection{Self-appointed, emergent and shared leaders were evident across the five GVTs.}

In GVT 1, no single individual emerged as a leader. Instead there was an attempt to develop shared leadership with every member taking on responsibility for the project. As one put it: "It was natural for us to expect a democratic co-leadership in university assignments" (GVT 1, UK). However, it was recognised that this was not working well because of the lack of a leader to take responsibility of the big picture in the team pro- 
cess. A Japanese RHUL member noted: "in my culture, it is a nature process for members to follow a leader and only in rare occasion where the leader needs to get a second opinion, another person may get involved".

In GVT 2, the UK based members made a conscious effort develop shared leadership. For this, they agreed in their first meeting that each meeting will be facilitated by a different member. This led to very good working relations among the dispersed members, to the point that a Norwegian student said: "I wish I was attending the presentation in the UK - I am curious to see how it all went".

"Though I have had industry experience I never worked in a virtual team setting; ... it is was an interesting and important project which added to my experiential projects ... a very useful experience for a future career in business" (GVT $2 \mathrm{UK}, \mathrm{M}$ ).

In GVT 3, some delays were exhibited in terms of starting the project with the first week gone and no communication was arranged among the VPT members. When this finally happened, the leadership role was shared among 2 members both in RHUL during the welcoming stage of the project. One of these individuals led the socialisation process and set up ice-breaker activities, while the second encourage communication about the skills that each member brought to the team and task allocation. When the second individual was absent in the second group meeting, the first individual took on the leadership role till the end of the project. The group was found to have worked well with their dispersed members and the Norwegian students' input to the presentation was clearly acknowledge and valued. Where collaboration suffered was among the UKbased members and it believed to be due to the cultural diversity of this group, with the Chinese and Indian students being particularly quiet: One of the emergent leaders acknowledged that though "The VPT was successful in socialising with the Norwegian students, we were less successful in socialising with the local students" (GVT3, UK, A). "This project was a good opportunity to improve our employability and career development" (GVT 3, UK F).

In GVT 4, an individual emerged as a leader early on in the project. His leadership style described by himself and others was seen as a transactional style due to being goal-orientated and task driven, aiming to direct, coordinate and correct members: "Our leader showed organisational skills and an ability to bring team members together through communication and enthusiasm" (GVT4, UK, M). The three stages of the VT lifecycle was acknowledged by team members, which reflected on the activities that took place within each stage. It was acknowledged that not enough effort was put in developing rapport and icebreaking activities in the welcoming stage, however according to another member, the leader was found to start each meeting by asking each member what they have been up to, thus making an effort on build social relations with other members. Also, it was felt that opportunities should have been created for other members to enact the leadership role too: "I should have allowed different members to take responsibility or facilitate the different meetings each week; as well as enhancing their skills, it would have enhanced their motivation and creativity too" (GVT 4, UK, Yu). "The Norwegian student stayed active and energetic throughout the project and we had the chance to embrace diversity in opinion, skills and background "(GVT 4, UK, M). 
In GVT 5, a UK based member was appointed as the team leader: "I was chosen as a leader by the RHUL members"; this indicates that the appointed was not discussed with the NTNU members according to whom: "Y put herself forward as the leader and we accepted it". It was acknowledged that this role was not discussed and that this was a case of a self-appointed leader early in the project. It was acknowledged that in this GVT, not enough time was spent in the welcoming stage and getting to know each other: "When given the opportunity to work in a VPT, if time allows, building rapport would be beneficial. Gaining a greater understanding of individual skill sets will also allow for better division of work ... as well as clearer expectations for all members involved" (GVT5, UK M).

\subsection{Students' Reflections on the student-based GVTs}

All students had the opportunity to reflect, both verbally and in writing, on the GVT collaboration following the completion of the project:

"The virtual project was a very valuable experience and it provided the opportunity to implement leadership theory and put into practice" (GVT 3, UK A).

"This experience can only make one wiser and make them more knowledgeable for future events" (GVT 4, UK S).

"The way we build trust among the group members was by meeting the deadlines the group agreed upon" (GTV 2, Norway).

"Online start-up meeting were extremely useful to get to know each other and establish team roles" (GTV 4, Norway).

UK students also reflected specifically on the e-leadership roles enacted within their GVT, commenting on their own leadership style and that by their fellow members. Some members showed a very good awareness of this role. For example: "our objective was to draw on the strengths and to overcome the challenges of working in a virtual setting...

“... with leadership our team increased in productivity and we were able to become more cohesive as a group" (GVT 3, UK A). Where a GVT only adopted the shared leadership style, it was felt that this did not work very effectively. Instead, in the case where shared leadership was accompanied by an emergent leader, the results were more positive both in terms of team performance and team dynamics.

Overall, it was shown in their reflections that students would welcome a more flexible, fluid and shared leadership approach where more members take on the role of the leader. They appreciated that this would enhance everyone's learning and improve their skills in working in the virtual team environment:

"When carrying out the role of an e-leader, I understood the underlying difference in contrast to working only locally" (appointed leader, GVT 5, UK Y). The same appointed leader however acknowledged in her reflection that the leadership role should be a more fluid one: "If provided, we had more time for project completion, this fluid inter-transferrable leadership position would be possible as well as exploration of more ideas and research topic wise" (GVT 5, UK Y). 


\section{$6 \quad$ Pedagogical Issues on using GVTs in Teaching}

Following their GVT experience, students were asked to make recommendations for improving these kind of projects. They identified three areas where in their views change was needed. We present these below and also add our response as instructors:

Students' recommendation 1: More time to be allocated to the project.

Instructors' response: The project had four weeks duration. Four out of five GVTs did not start the GVT meeting until the second week of the project and after being prompted by the instructor. In one case, the UK-based members had an initial meeting without inviting their Norwegian collaborators. A pedagogical implication of this is that students need to be reminded that virtual teams often operate on a temporary, short term basis. Nevertheless, all three stages of the VT lifecycle should be implemented with particular emphasis being given to the welcoming stage where all members need to be included. Developing rapport and social relations are crucial at this early stage of the team process for promoting team identity and collaboration.

Student Recommendation 2: The meeting with the industry expert to take place earlier in the project in order to clarify project aims.

Instructors' response: Though the need to clarify project aims at the earliest possible as this is important for the project development, it is also acknowledged that students should be given the chance to figure out the project aims themselves. In this case the aims had flexibility and therefore students could bring their own ideas as to how to approach the project. The industry expert also agreed with this view by adding: "part of the journey to success is realising which resources are available and (how) to make best use of them (:)" (industry expert, email).

A criticism given to existing studies that used student-based GVTs is that these are not always realistic team settings as the students tend to get very clear instructions as to what the task is about and therefore what is expected of them in order to fulfil the task. The reason for giving clear instructions is of course linked to the need to systematically measure students' performance. Outside academia however, virtual team members may not have clear goals. Instead, project members need to spend time developing the goals of their team. For example, it has been argued that student-based VTs experience limited team dynamics and interactions which may be necessitate efforts to clarify team goals and expectations and therefore cannot represent real-life business environments where power dynamics prevail [5]. Similarly, research has shown that it is more likely for a virtual team to experience high levels of trust when its members work together to develop the goals of their team than those teams whose members do not spend time to develop a shared understanding of what the team goals are [18].

Student Recommendation 3: The need for the project deliverables to be the same across the different member groups in the different universities.

Instructors' response: We readily acknowledge that this is important. In our case, this was not possible for the specific project as the instructors in Norway had already made arrangements for alternative assessments. Therefore whilst the UK based students 
were assessed on the group presentation, the Norwegian students were not, even though they were asked to make a contribution and collaborate with the UK based members to jointly develop the presentation.

These pedagogical issues can be summarised as follows:

- Instructors should emphasize the temporal dimension of VPTs and that students need to make the most of the time they have available working on the project.

- To make it more realistic for students, instructors should give a degree of flexibility to students to set up their own specific objectives, guided by the general goals of the project.

- The universities involved should agree on common deliverables and assessment methods.

\section{$7 \quad$ Conclusions and Implications}

The main aim of this study has been to develop a better understanding of the leadership practices adopted in student based GVTs. It has been driven by our position that leadership has an impact on effective collaborations in the dispersed setting. Using the case of a virtual collaborative project set up between a university in the UK and a university in Norway, it was found that the way leadership was enacted had a role to play in the collaboration within the GVT. The teams with self-appointed leaders were found not to have put significant effort in developing team relationships and trust which are prerequisites for effective collaborations. For all team members, this was the first time that they had worked on a virtual collaborative project. In their reflections, they all acknowledged that despite the problems and difficulties experienced, through the GVT project, they were able to understand the role and important of effective leadership practices and appreciate some of the norms needed to facilitate virtual team success. Moreover, the findings suggest that GVT leaders, either appointed or emergent, should encourage social interactions at an early stage of the GVT in order to enhance team dynamics, avoid isolation and improve interpersonal relations among virtual team members. Such practices are effective ice-breakers and can increase the opportunities for collaboration.

Overall, giving the opportunity to students to lead and not just be part of GVTs can contribute to invaluable experiences and can enhance students' employability and career development.

\section{References}

1. Ahuja, M. K. and J. E. Galvin: Socialization in Virtual Groups. J. of Management. 29: pp.161 (2003)

2. Alavi, M., Wheeler, B. C., \& Valacich, J. S.: Using IT to reengineer business education: An exploratory investigation of collaborative telelearning. MIS quarterly, 293-312 (1995).

3. Alavi, M., Yoo, Y., \& Vogel, D. R.: Using information technology to add value to management education. Academy of Management Journal, 40(6): 1310-1333 (1997). 
4. Carte, T. A., Chidambaram, L., \& Becker, A.: Emergent leadership in self-managed virtual teams. Group Decision and Negotiation, 15(4), 323-343 (2006).

5. Chamakiotis, P., \& Panteli, N.: Leading the creative process: the case of virtual product design. New Technology, Work and Employment, 32(1), 28-42 (2017).

6. Cramton, C. D.: Information Problems in Dispersed Teams. Annual Meeting of the Academy of Management (Best Papers Proceedings), Boston, MA (1997).

7. Cramton, C. D.: 'Attribution in Distributed Work Groups'. Distributed Work. S. Kiesler, The MIT Press: pp.191 (2002)

8. Davison, R. M., Fuller, M. A., \& Hardin, A.: E-consulting in virtual negotiations. Group Decision and Negotiation, 12(6), 517-535 (2003).

9. Davison, R. M., Panteli, N., Hardin, A. M., \& Fuller, M. A.: Establishing effective global virtual student teams. IEEE Transactions on Professional Communication, 60(3), 317-329 (2017).

10. Germain, M. L., \& McGuire, D.: The role of swift trust in virtual teams and implications for human resource development. Advances in Developing Human Resources, 16(3), 356-370 (2014).

11. Jarvenpaa, S. L. and D. E. Leidner: 'Communication and Trust in Global Virtual Teams'. J. of Computer-Mediated Communication (Online at http://www.ascusc.org/jcmc) 3(4) (1998).

12. Kayworth, T. R., \& Leidner, D. E.: Leadership effectiveness in global virtual teams. Journal of management information systems, 18(3), 7-40 (2002).

13. Kotlarsky, J. and I. Oshri: 'Social ties, knowledge sharing and successful collaboration in globally distributed system development projects'. European Journal of Information Systems 14(1), 37-48 (2005).

14. Malhotra, A., Majchrzak, A., \& Rosen, B.: Leading Virtual Teams. The Academy of Management Perspectives, 21, 60-70 (2007).

15. Northcraft, G. B., Griffith, T. L., \& Fuller, M. A.: Virtual study groups: A challenging centerpiece for "Working Adult" management education. In S. P. Ferris \& S.H. Godar, (Eds.), Teaching and learning with virtual teams. Idea Group Publishing (2006).

16. Panteli, N., \& Davison, R. M.: The role of subgroups in the communication patterns of global virtual teams. IEEE Transactions on Professional Communication, 48(2), 191-200 (2005).

17. Panteli, N., \& Duncan, E.: Trust and temporary virtual teams: alternative explanations and dramaturgical relationships. Information Technology \& People, 17(4), 423-441 (2004).

18. Panteli N. and Tucker R.: Power and trust in global virtual teams, Communications of the ACM, vol. 52, no. 12, pp. 113-115, 2009 (2009).

19. Piccoli, G., Ahmad, R., \& Ives, B.: Web-based virtual learning environments: A research framework and a preliminary assessment of effectiveness in basic IT skills training. MIS quarterly, 401-426 (2001).

20. O'Mahony, S \& Ferraro, F.: The emergence of governance in an open source community. Academy of Management Journal, 50(5), 1079-1106 (2007).

21. Robey, D., Schwaig, K. S., \& Jin, L.: Intertwining material and virtual work. Information and organization, 13(2), 111-129 (2003).

22. Roschelle, J. and S. Teasley: The construction of shared knowledge in collaborative problem solving. Computer Supported Collaborative Learning. C. E. O'Malley. Heidelberg, SpringerVerlag, 69-97 (1995).

23. Qureshi, S., I. Bogenrieder and K. Kumar: Managing Participative Diversity in Virtual Teams: Requirements for Collaborative Technology Support. 33rd Hawaii International Conference on Systems Sciences, IEEE (2000).

24. Sarker, S., \& Sahay, S.: Understanding virtual team development: An interpretive study. J. of the association for information systems, 4(1), 1 (2003). 
25. Vogel, D. R., Genuchten, M., Lou, D., van Eekhout, M., Verveen, S., \& Adams, T.: Exploratory research on the role of national and professional cultures in a distributed learning project. IEEE Transactions on Professional Communication, 44(2), 114-125 (2001).

26. Yoo, Y.\& Alavi, M.: Emergent Leadership in Virtual Teams: What do Emergent Leaders Do? Information and Organization, 14(1), 27-58 (2004).

27. Zander, L., Mockaitis, A.I., and Butler, C.L.: Leading global teams, J. of World Business, Vol. 47 No. 4, 592-603 (2012)

28. Zander, L., Zettinig, P. and Makela, K.: Leading global virtual teams to success, Organizational Dynamics, Vol. 42 No. 3, 228-237 (2013). 